\title{
Author Correction: A phase 1/2 trial of an immune-modulatory vaccine against IDO/PD-L1 in combination with nivolumab in metastatic melanoma
}

Julie Westerlin Kjeldsen (D, Cathrine Lund Lorentzen, Evelina Martinenaite, Eva Ellebaek (D, Marco Donia (D), Rikke Boedker Holmstroem (10, Tobias Wirenfeldt Klausen, Cecilie Oelvang Madsen, Shamaila Munir Ahmed, Stine Emilie Weis-Banke (1D), Morten Orebo Holmström, Helle Westergren Hendel, Eva Ehrnrooth, Mai-Britt Zocca, Ayako Wakatsuki Pedersen, Mads Hald Andersen and Inge Marie Svane (B)

Correction to: Nature Medicine https://doi.org/10.1038/s41591-021-01544-x, published online 9 December 2021.

This paper was originally published under standard Springer Nature license (๔ The Author(s), under exclusive licence to Springer Nature America, Inc.). It is now available as an Open Access paper under a Creative Commons Attribution 4.0 International license, (c) The Author(s). The error has been corrected in the HTML and PDF versions of the article.

Open Access This article is licensed under a Creative Commons Attribution 4.0 International License, which permits use, sharing, adaptation, distribution and
reproduction in any medium or format, as long as you give appropriate credit to the original author(s) and the source, provide a link to the Creative Commons
license, and indicate if changes were made. The images or other third party material in this article are included in the article's Creative Commons license, unless
indicated otherwise in a credit line to the material. If material is not included in the article's Creative Commons license and your intended use is not permitted by statutory regulation
or exceeds the permitted use, you will need to obtain permission directly from the copyright holder. To view a copy of this license, visit http://creativecommons.org/licenses/by/4.0/.
Published online: $8 \mathrm{March} 2022$
https://doi.org/10.1038/s41591-022-01771-W
(C) The Author(s) 2022

\section{Author Correction: Before the heart attack}

Ellen E. Blaak (1) and Willem M. de Vos (D)

Correction to: Nature Medicine https://doi.org/10.1038/s41591-022-01685-7, published online 17 February 2022.

In the version of this article initially published, a composition error appeared in the second sentence of the Fig. 1 caption. In the text now reading "Microbial pathways related to short-chain fatty acid (SCFA) metabolism are already reduced and those related to branched-chain amino acid (BCAA) metabolism increased in metabolically matched controls relative to healthy controls, prior to IHD diagnosis," the terms "reduced" and "increased" were reversed. The error has been corrected in the HTML and PDF versions of the article.

Published online: 9 March 2022

https://doi.org/10.1038/s41591-022-01764-9

(c) Springer Nature America, Inc. 2022 